\title{
Effect of Cupping Therapy on Range of Motion, Pain Threshold, and Muscle Activity of the Hamstring Muscle Compared to Passive Stretching
}

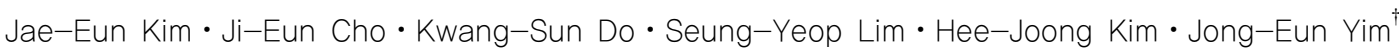

Dept. of Physical Therapy, The Graduate School of Sahmyook University, Seoul, Korea

Received: May 31, 2017 / Revised: June 19, 2017 / Accepted: July 28, 2017

(c) 2017 J Korean Soc Phys Med

\section{| Abstract |}

PURPOSE: Flexibility and range of motion are very important factors in sports performance, rehabilitation, and musculoskeletal pain. The purpose of this study was to measure the effects of cupping therapy on flexibility, muscle activity, and pain threshold of hamstring muscle compared to passive stretching in healthy subjects.

METHODS: Thirty healthy subjects were randomly assigned in a crossover design to cupping therapy and passive stretching. Subjects were tested to compare their effects according to the intervention such as Passive range of motion (PROM) (straight leg raising) and active range of motion (AROM). And algometer (pain) testing and MVC assessment using EMG were performed as dependent variables.

RESULTS: The cupping therapy group and passive stretching group showed significant differences in all variables including PROM $(p=.00, p=.00), \operatorname{AROM}(p=.00$, $p=.03$ ), Pain Threshold ( $p=.03, p=.08)$, Semitendinosus $\operatorname{MVC}(p=.01, p=.00)$, and Biceps femoris MVC $(p=.01$, $p=.16)$. There were no significant differences between the

$†$ Corresponding Author : jeyim@syu.ac.kr

This is an Open Access article distributed under the terms of the Creative Commons Attribution Non-Commercial License (http://creativecommons.org/licenses/by-nc/3.0) which permits unrestricted non-commercial use, distribution, and reproduction in any medium, provided the original work is properly cited. two groups in all variables.

CONCLUSION: These findings of this study suggested that cupping therapy has as much positive effect on flexibility, pain threshold, and muscle contraction as passive stretching. Also, it is more convenient and easier to work on patients than passive stretching. Therefore, cupping therapy should be considered as another option to treat range of motion, pain, and muscle activity in the clinical field.

Key Words: Cupping therapy, Hamstring muscle, Pain, Passive stretching, Range of motion

\section{Introduction}

Flexibility and range of motion are very important factors in sports performance, rehabilitation, and musculoskeletal pain (Decoster et al., 2004; Decoster et al., 2005; Law et al., 2009; Kim et al., 2011). Flexibility can be defined as the capacity for muscle extension to enable movement of a joint within its range of motion, and is a crucial component of normal biomechanic function (Zachazewski, 1989; Hopper et al., 2005).

The hamstring muscle is one of the principle elements in rehabilitation programs and sports activities that enable recovery of optimal muscle length (Fasen et al., 2009; Kim et al., 2014). The hamstring is most widely used in 
stretching studies because it is a biarticular muscle that can be extended without impedance by an articular capsule or ligament (Ylinen et al., 2010). Moreover, decreased flexibility in the hamstring muscle disturb the biomechanics of the waist and pelvis, leading to low back pain or musculoskeletal disorders (Witvrouw et al., 2003; Meroni et al., 2010; Muyor et al., 2011; Kim and Hwang, 2012; Rogan et al., 2013). Therefore, it is clinically very important to maintain adequate length.

Passive stretching is the most widely used method to extend the length of muscles, and is the most used intervention to enhance the flexibility of muscles and increase the range of motion; however, there have been reports that question the beneficial effect of stretching on exercise performance because extension of muscle length may lead to decreased strength (Marek et al., 2005; You and Lee, 2010).

Cupping therapy is a type of alternative medicine for pain relief, and for treatment in addition to acupuncture therapy (Tham et al., 2006). Cupping therapy has been used for various illnesses to headache, low back pain, neck pain and carpal tunnel syndrome (Ahmadi et al., 2008; Farhadi et al., 2009; Michalsen et al., 2009; Lauche et al., 2011). Cupping therapy has been recommended for treatment of musculoskeletal disorders following publication of various studies (Ahmadi et al., 2008; Farhadi et al., 2009; Michalsen et al., 2009; Lauche et al., 2011), and is expected to become a new trend in sports medicine when applied in combination with use of movement patterns or functional exercises (Lacross, 2014; Musumeci, 2016; Ries, 2016).

Based on prior studies, the effects of cupping therapy can be divided into mechanical and chemical components. The mechanical effects induce free movement of deep fascia and muscles by activating lubrication of superficial fascia between skin and deep fascia (Guimberteau et al., 2010). This eases the restriction caused by adhesion of the deep fascia and enables independent movement of muscle by intensive application of cupping therapy (Tham et al., 2006). In addition, cupping therapy reportedly maintains normal physical function through an immediate reaction by skin and fascia (Benjamin, 2009). Lastly, it removes the tension in soft tissues caused by pain and relieves mechanical deficits by efficiently restoring the tissues (Malliaropoulos et al., 2004).

Studies on the chemical effects reported that efficient physical recovery was possible with application of cupping therapy, as it increased blood flow and removed toxins from the deep fascia (Yoo and Tausk, 2004; Tham et al., 2006; El Sayed et al., 2013). Cupping therapy also stimulated small nerves in muscle and induced secretion of endorphins in the brain in response to application of cupping therapy to the skin (Tham et al., 2006).

Although many studies scientifically demonstrated the effects of cupping therapy (Yoo and Tausk, 2004; Tham et al., 2006; Ahmadi et al., 2008; Farhadi et al., 2009; Michalsen et al., 2009; Lauche et al., 2011; El Sayed et al., 2013; Hanan and Eman, 2013), there is a lack of studies on changes in muscle length, muscle activity, and pain thresholds. Therefore, the purpose of this study is to measure and compare the change in flexibility, muscle activity, and pain threshold in hamstring muscle with application of cupping therapy and static stretching.

\section{Methods}

\section{Participants}

The subjects of this study were 30 healthy males and females in their $20 \mathrm{~s}$ and 30 's who were students attending $\mathrm{S}$ University in Seoul. The subjects voluntarily agreed to participate in the experiment, and those without lower limb muscle pain, restriction in range of motion (ROM), backache, disc disease, or an open wound at surface electromyogram (SEMG) attachment sites were selected. The characteristics of subjects are shown in Table 1. All experimental protocols and procedures were explained to 
Table 1. General characteristics

\begin{tabular}{lcc}
\hline & & \multicolumn{2}{c}{ Subjects $(\mathrm{N}=15)$} \\
\hline \multirow{2}{*}{ Sex } & Male & $12(80 \%)$ \\
& Female & $3(20 \%)$ \\
\hline \multicolumn{2}{c}{ Age $($ years $)$} & $30.10 \pm 5.52$ \\
Height $(\mathrm{cm})$ & $167.38 \pm 8.82$ \\
Weight $(\mathrm{kg})$ & $59.98 \pm 12.14$ \\
\hline
\end{tabular}

Mean \pm SD

each subject and approved by the institutional review board of Sahmyook University in Korea. All subjects provided written informed consent prior to study enrollment.

\section{Procedure}

After pre-test, subjects were randomly divided into cupping therapy group and passive stretching group by coin-tossing method. Three physical therapists with greater than 3 years' experience conducted stretching and cupping therapy intervention and each of the four testing sessions

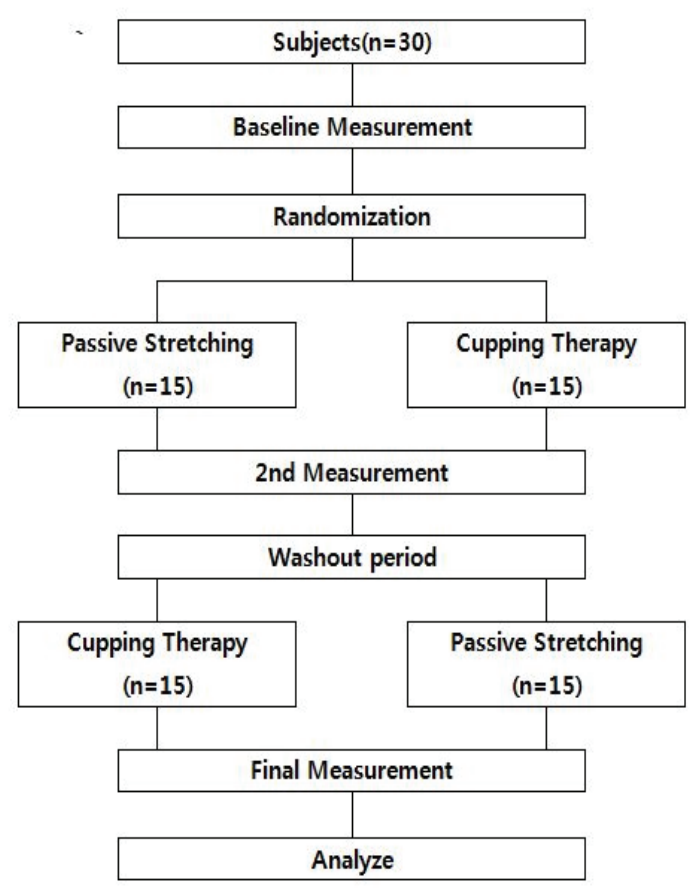

Fig. 1. Study design under the same environmental conditions. Participants were not blinded to the intervention. Only the testers were blinded.

Cupping therapy was applied to the hamstring muscle for 5 minutes in the cupping therapy group. The passive stretching group was treated with a passive stretching for 10 seconds and repeated 9 times. Then, a post test was conducted after ether cupping therapy or passive stretching, in a manner similar to that of the pretest. Passive range of motion (PROM) (straight leg raising), active range of motion (AROM), and algometer (pain) testing, and MVC assessment using EMG were performed as dependent variables. After 1 week of washout period, following a pretest, subjects were switched to the other group. Then, a posttest was conducted, in a manner similar to that of the pretest (Fig. 1).

\section{Interventions}

\section{1) Cupping Therapy}

Cupping therapy can be applied either with the use of a suction pump or by briefly heating the inside of a glass cup with a flame. Cupping therapy is usually applied with a suction pump but there is a gradual increase in the use of heat for cupping therapy due to outstanding treatment effects and convenience in sterilization. The application time varies based on the reason for treatment and intensity of negative pressure, but the application time is usually 1-10 minutes (Tham et al., 2006). Accordingly, the assessment was conducted in this study after a 5-minute application of cupping therapy with the use of a flame.

In flame-heated cupping therapy, the inside of the glass cup momentarily develops a vacuum. When the glass cup is applied to the skin, the negative pressure within the cup causes myofascial decompression. To apply cupping therapy to the hamstring muscle in the experiment leg group, the muscle was divided into 3 areas and 3 cupping therapy cups were applied to each area (Fig. 2). 


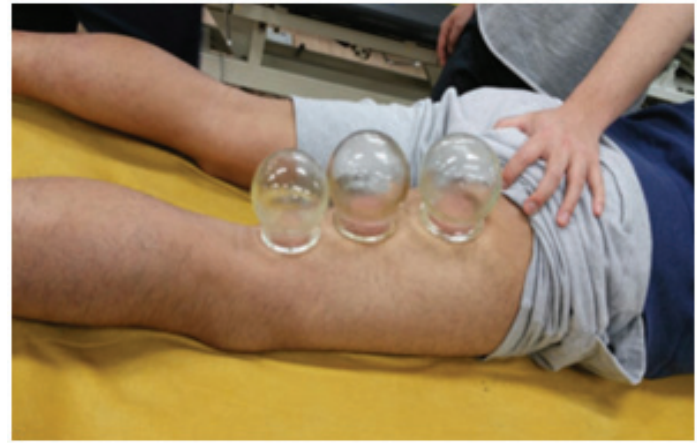

Fig. 2. Attachment point of cupping therapy

\section{2) Passive stretching}

Subjects lay supine keeping their backs flat throughout the stretch. The leg was passively raised until to the point of "slight discomfort" in the hamstring and held for 10 seconds, followed by a and slow return; this was repeated 9 times (Johnson et al., 2014).

\section{Measurement}

In order to verify treatment efficacy of cupping therapy and passive stretching, a pre and posttest were conducted. ROM, algometer, and MVC tests were conducted before and after the intervention.

\section{1) ROM Test}

PROM and AROM testing were conducted. PROM was conducted with the subject in supine position on a medical bed. The distance between the greater trochanter and the knee joint was indicated with a straight line for the PROM test, and an electronic goniometer (Dualer IQ, J-tech Medical, USA) was attached to the femoral region on the indicated line. Measurement was conducted after setting the value in the supine position at zero. Examiner performed the passive SLR by keeping the knee in full extension and the ankle in neutral position. Full ankle dorsiflexion was avoided to prevent calf muscle stiffness or pain (gastrocnemius and soleus) from confounding the sensation of hamstring stiffness and pain which would signal the limit of the SLR test. The examiner would hold the talus and avoid any hip rotation during flexion of the hip as they lifted the subject's lower limb until he or she first complained of stiffness or pain in the region of the thigh, bent his/her knee, or began to swing into a posterior pelvic tilt (noted as movement of the ASIS).

For AROM, the hip joint angle was measured after voluntary straight leg raising. For this measurement, the ankle was held in ankle neutral position and the leg was lifted slowly to avoid generating elasticity from a quick leg lift. This measurement was within a range that would not cause bending of the knee on the measured side or an increase in lumbar lordosis angle.

\section{2) Pain Threshold Test}

The pain threshold value based on pressure applied to the hamstring muscle was measured with the use of an electronic algometer (Algometer, J-tech Medical, USA) with the subject in prone position on a medical bed. Three areas $2 \mathrm{~cm}$ apart from the cupping place on the hamstring muscle were selected as pain points and the average value for the 6 pain points was calculated to obtain the pain index.

\section{3) EMG test}

Wireless EMG electrodes were attached to the semitendinosus (ST) and biceps femoris (BF) with the subject in prone position on a medical bed. Before attachment of electrodes, hair at the attachment area was removed, and the keratin layer was removed to reduce impedance to the myoelectric signal by rubbing; electrodes were then attached after cleansing the skin 3-4 times with a sterilized alcohol swab. EMG electrodes were attached along the contracting direction of the muscle fibers. The ST electrode was attached at the midpoint between the ischial tuberosity (IT) and the halfway point to the medial condyle in the femoral region. The BF electrode was attached at the midpoint from the IT to the halfway point 
of the lateral condyle in the femoral region (Konrad, 2005; Shenoy et al., 2010). The distance between wireless electrodes was 2-3 cm. Muscle activity during sustained isometric MVC for 5 seconds with the knee held in $90^{\circ}$ knee flexion was measured.

\section{Data Analysis}

Data collected in this study were analyzed with SPSS 18.0 for Windows and a statistically significant level a was set as .05 . In order to compare the differences between the 2 groups before experiment for homogeneity verification, an independent t-test was conducted. Normality was verified by conducting a Kolmogorov-Smirnov test for the 2 groups. The differences between the groups were compared with an independent parametric t-test, and a paired t-test was used to compare results for ROM, pain, and EMG before and after intervention in the experiment and control groups.
III. Results

There was a statistically significant increase in ROM after intervention in the cupping therapy and passive stretching group for both the PROM and AROM tests. However, there was no significant difference between the 2 groups for both tests (Table 2, 3).

The pain threshold increased from 56.1 to 63.8 before and after the intervention in the cupping therapy group $(\mathrm{p}<.05)$. However, there was no statistically significant difference in the Passive stretching group from 53.3 to $58.2(\mathrm{p}<.05)$. In a comparison of the 2 interventions, there was no difference between the groups (Table 4).

The muscle activity value of the ST increased from 175.4 $\mu \mathrm{V}$ to $214.9 \mu \mathrm{V}$ before and after the intervention in the cupping therapy group $(\mathrm{p}<.05)$. The muscle activity value of the ST increased from $176.0 \mu \mathrm{V}$ to $210.8 \mu \mathrm{V}$ before and after the intervention in the passive stretching group

Table 2. Comparison of Cupping Therapy and Passive stretching on PROM

\begin{tabular}{lcccc}
\hline & $\begin{array}{c}\text { Cupping therapy } \\
(n=15)\end{array}$ & $\begin{array}{c}\text { Passive stretching } \\
(n=15)\end{array}$ & $t$ & $p$ \\
\hline Before (angle, $\left.{ }^{\circ}\right)$ & $64.6 \pm 9.085$ & $64.8 \pm 10.23$ & -.75 & .940 \\
After (angle, $\left.{ }^{\circ}\right)$ & $76.0 \pm 10.65$ & $75.1 \pm 11.09$ & .218 & .829 \\
Difference & $11.4 \pm 8.46$ & $10.2 \pm 7.67$ & .384 & .704 \\
$t$ & -5.215 & -5.180 & & \\
$P$ & $.000^{*}$ & $.000^{*}$ & & \\
\hline
\end{tabular}

mean \pm standard deviation

Table 3. Comparison of Cupping Therapy and Passive stretching on AROM

\begin{tabular}{lcccc}
\hline & $\begin{array}{c}\text { Cupping therapy } \\
(n=15)\end{array}$ & $\begin{array}{c}\text { Passive stretching } \\
(n=15)\end{array}$ & $t$ & $p$ \\
\hline Before (angle, $\left.{ }^{\circ}\right)$ & $55.5 \pm 9.26$ & $56.5 \pm 9.65$ & -.280 & .728 \\
After (angle, $\left.{ }^{\circ}\right)$ & $66.8 \pm 7.68$ & $66.6 \pm 14.34$ & .35 & .972 \\
Difference & $12.3 \pm 7.04$ & $10.6 \pm 12.59$ & .405 & .689 \\
$t$ & -5.160 & -2.587 & & \\
$P$ & $.000^{*}$ & $.025^{*}$ & \\
\hline
\end{tabular}

mean \pm standard deviation 
Table 4. Comparison of Cupping Therapy and Passive stretching on Pain Threshold

\begin{tabular}{lcccc}
\hline & $\begin{array}{c}\text { Cupping therapy } \\
(n=15)\end{array}$ & $\begin{array}{c}\text { Passive stretching } \\
(n=15)\end{array}$ & $t$ & $P$ \\
\hline Before Pain & ${ }^{\dagger} 56.1 \pm 11.16$ & $53.3 \pm 10.06$ & .738 & .467 \\
After Pain & $63.8 \pm 12.71$ & $58.2 \pm 12.04$ & 1.235 & .227 \\
Difference & $7.6 \pm 12.47$ & $4.8 \pm 9.88$ & .663 & .513 \\
$t$ & -2.365 & -1.918 & & \\
$P$ & $.033^{*}$ & .076 & & \\
\hline
\end{tabular}

Table 5. Comparison of Cupping Therapy and Passive stretching on Semitendinosus-EMG

\begin{tabular}{lcccc}
\hline & $\begin{array}{c}\text { Cupping therapy } \\
(n=15)\end{array}$ & $\begin{array}{c}\text { Passive stretching } \\
(n=15)\end{array}$ & $t$ & $p$ \\
\hline Before- MVC $(\mu \mathrm{V})$ & ${ }^{+} 175.4 \pm 98.94$ & $176.0 \pm 58.08$ & -.202 & .984 \\
After- MVC $(\mu \mathrm{V})$ & $214.9 \pm 115.07$ & $210.8 \pm 71.75$ & .118 & .072 \\
Difference & $39.5 \pm 50.50$ & $34.8 \pm 39.86$ & .285 & .778 \\
$t$ & -3.035 & -3.384 & & \\
$P$ & $.009^{*}$ & $.004^{*}$ & & \\
\hline
\end{tabular}

${ }^{\dagger}$ mean \pm standard deviation

Table 6. Comparison of Cupping Therapy and Passive stretching on Biceps femoris -SEMG

\begin{tabular}{lcccc}
\hline & $\begin{array}{c}\text { Cupping therapy } \\
(n=15)\end{array}$ & $\begin{array}{c}\text { Passive stretching } \\
(n=15)\end{array}$ & $t$ & $P$ \\
\hline Before- MVC $(\mu \mathrm{V})$ & $+115.2 \pm 57.40$ & $80.0 \pm 44.47$ & 1.877 & .907 \\
After- MVC $(\mu \mathrm{V})$ & $132.5 \pm 64.18$ & $128.1 \pm 130.6$ & .116 & .908 \\
Difference & $17.3 \pm 22.87$ & $48.1 \pm 126.0$ & -.932 & .359 \\
$T$ & -2.938 & -1.481 & & \\
$P$ & $.011^{*}$ & .161 & & \\
\hline${ }^{+}$mean \pm standard deviation & & &
\end{tabular}

$(\mathrm{p}<.05)$. In a comparison of the 2 interventions, there was no difference between the two groups (Table 5).

The muscle activity value of the BF increased from $115.2 \mu \mathrm{V}$ to $132.5 \mu \mathrm{V}$ before and after the intervention in the cupping therapy group $(p<.05)$. In Passive stretching group, muscle activity value of BF increased from $80.0 \mu \mathrm{V}$ to $128.1 \mu \mathrm{V}$, but there was no statistically significant difference $(\mathrm{p}<.05)$. In a comparison of the 2 interventions, there was no difference between the two groups (Table 6).

\section{Discussion}

In order to evaluate the effect of MFD (Myofascial Decompression, cupping) and passive stretching on ROM, pain threshold, and muscle activity of hamstring muscles, this study was conducted with 15 normal adults without musculoskeletal disorders. There was a significant increase in ROM after the intervention with both cupping therapy and passive stretching. In prior studies, there was a statistically significant increase in ROM in a comparison of a 
cupping therapy intervention group and a foam roll \& heat pack intervention group in 17 collegiate athletes. This study also found the same result as the preceding study, which implies that cupping therapy has a positive impact on an increase in flexibility of muscle (Lacross, 2014). The reason why cupping therapy may induce as much change in flexibility as passive stretching can be explained by research findings that suggest a mechanical basis for its effects; cupping therapy generates effective manipulation of physical structures including fascia, skin, and musculocutaneous tissues, increases the neurophysiological activity at the level of nociceptors, the spinal cord, and other nerves, and ultimately leads to significant relaxation (Musial et al., 2013). In addition, negative pressure generated by application of an cupping therapy cup is about 4 inches removed from soft tissues and exerts various mechanical effects including the relief of muscular pain, restoration of muscle, recovery from adhesions, and release of tissues bound up within muscle (Hanan and Eman, 2013).

The precise physiological mechanism of pain alleviation by cupping therapy remains unclear, but there are several theories. First, chemical transmitters, such as serotonin, endorphin, and cortisol, which can block pain are secreted during cupping therapy, as occurs with acupressure or acupuncture, and play a role in ultimately reducing pain (Schulte, 1996). Second, nociceptor activation induces pain (Schaible et al., 2002), and it is suggested that cupping therapy alleviates pain by its anti-nociceptive effect and counter irritation (Michalsen et al., 2009). Third, all noninvasive and non-drug treatments have a placebo effect; a recent research finding suggested that a placebo-device is more effective in pain alleviation compared to placebo-pill (Kaptchuk et al., 2006).

Muscle activity analysis showed a significant increase in in the ST and semimembranosus muscles for both interventions in the cupping therapy and passive stretching groups. In regards to $\mathrm{BF}$, there was a significant increase in muscle activity after the intervention in the cupping therapy group alone. Moreover, there was an increase in muscle activity followed by an increase in flexibility of the muscle after cupping therapy treatment, which can be explained by the interaction between muscle length and tension. Many studies have suggested that there is a correlation between muscle flexibility and muscle strength. At optimal muscle length, it has been suggested that there are corresponding serial sarcomere numbers (Cox et al., 2000; Coutinho et al., 2004), and that these serial sarcomere numbers can be increased with flexibility exercises (Ferreira et al., 2007; Chen et al., 2011). It has also been suggested that muscle strength may have an influence on adaptation of serial sarcomere numbers, and that an increase in serial sarcomere numbers has an influence on muscle strength (Koh, 1995). It can be surmised that the flexibility generated by cupping therapy and passive stretching in this study had an effect on sarcomeres and that an increase in muscle activity was followed by an improved sarcomere environment with an increased serial sarcomere number. Additionally Report of Coutinho suggests that muscle fiber performance may be enhanced by an increase in the number of muscle fibers and the cross-sectional area of the muscle fibers after muscle stretching (Coutinho et al., 2006). Thus, as in this study, the significant increase in muscle activity after application of a Cupping therapy can be explained by this therapeutic mechanism.

A limitation of this study is that it examined the therapeutic effect for only a single application, and no assessment was performed regarding the duration of the application. Moreover, the correlation between sufficient rest and pre-intervention may be ambiguous since this was examined on the same day through the crossover design. Although cupping therapy was performed by experienced therapists, the negative pressure may not have been controlled either qualitatively or quantitatively. Lastly, the results will be more reliable when applied to more subjects since the number was small in this study.

Future study is needed using various cupping therapy 
techniques and ROM evaluation that combines cupping therapy and exercise. Moreover, a study of whether longterm application of cupping therapy has an effect on not only physical and physiological parameters but also on psychological aspects and quality of life should also be conducted.

\section{Conclusion}

The aim of this study is to measure the effects of cupping therapy on flexibility, muscle activity, and pain threshold of hamstring muscle compared to passive stretching. It was evident from findings of this study that cupping therapy has as much positive effect on flexibility, pain threshold, and muscle contraction as passive stretching. The cupping therapy could be a new clinical method to improve range of motion and it also could be an alternative tool for patients who cannot conduct the stretching exercise. Also, it is more convenient and easier to work on patients than passive stretching. Therefore, cupping therapy could be considered as another option to treat pain, ROM, and muscle activity in the clinical field.

\section{Acknowledgements}

This study is supported by the Graduate School of Sahmyook University.

\section{References}

Ahmadi A, Schwebel DC, Rezaei M. The efficacy of wet-cupping in the treatment of tension and migraine headache. Am J Chin Med. 2008;36(1):37-44.

Benjamin M. The fascia of the limbs and back-a review. J Anat. 2009;214(1):1-18.
Chen $\mathrm{CH}$, Nosaka K, Chen HL, et al. Effects of flexibility training on eccentric exercise-induced muscle damage. Med Sci Sports Exerc. 2011;43(3):491-500.

Coutinho EL, DeLuca C, Salvini TF, et al. Bouts of passive stretching after immobilization of the rat soleus muscle increase collagen macromolecular organization and muscle fiber area. Connect Tissue Res. 2006;47(5): 278-86.

Coutinho EL, Gomes AR, Franca CN, et al. Effect of passive stretching on the immobilized soleus muscle fiber morphology. Braz J Med Biol Res. 2004;37(12): 1853-61.

Cox VM, Williams PE, Wright H, et al. Growth induced by incremental static stretch in adult rabbit latissimus dorsi muscle. Exp Physiol. 2000;85(2):193-202.

Decoster LC, Cleland J, Altieri C, et al. The effects of hamstring stretching on range of motion: a systematic literature review. J Orthop Sports Phys Ther. 2005;35(6): 377-87.

Decoster LC, Scanlon RL, Horn KD, et al. Standing and Supine Hamstring Stretching Are Equally Effective. J Athl Train. 2004;39(4):330-4.

El Sayed S, Mahmoud H, Nabo M. Medical and scientific bases of wet cupping therapy (Al-hijamah): in light of modern medicine and prophetic medicine. Altern Integr Med. 2013:1-16.

Farhadi K, Schwebel DC, Saeb M, et al. The effectiveness of wet-cupping for nonspecific low back pain in Iran: a randomized controlled trial. Complement Ther Med. 2009;17(1):9-15.

Fasen JM, O'Connor AM, Schwartz SL, et al. A randomized controlled trial of hamstring stretching: comparison of four techniques. J Strength Cond Res. 2009;23(2): 660-7.

Ferreira GN, Teixeira-Salmela LF, Guimaraes CQ. Gains in flexibility related to measures of muscular performance: impact of flexibility on muscular performance. Clin J Sport Med. 2007;17(4):276-81. 
Guimberteau J, Delage J, McGrouther D, et al. The microvacuolar system: how connective tissue sliding works. J Hand Surg Eur Vol. 2010;35(8):614-22.

Hanan S, Eman S. Cupping therapy (Al-Hijama): It's impact on persistent non-specific lower back pain and client disability. Life Sci J. 2013;10:631-42.

Hopper D, Deacon S, Das S, et al. Dynamic soft tissue mobilisation increases hamstring flexibility in healthy male subjects. Br J Sports Med. 2005;39(9):594-8; discussion 8 .

Johnson AW, Mitchell UH, Meek K, et al. Hamstring flexibility increases the same with 3 or 9 repetitions of stretching held for a total time of 90 s. Phys Ther Sport. 2014; 15(2):101-5.

Kaptchuk TJ, Stason WB, Davis RB, et al. Sham device v inert pill: randomised controlled trial of two placebo treatments. Bmj. 2006;332(7538):391-7.

Kim DH, Kim TH, Jung DY, et al. Effects of the Graston Technique and Self-myofascial Release on the Range of Motion of a Knee Joint. J Korean Soc Phys Med. 2014;9(4):455-63.

Kim GC, Hwang BG. Kinetic analysis on the lumbar at the trunk flexion according to the degree of hamstring flexibility of healthy adult. J Korean Soc Phys Med. 2012;7(4):501-7.

Kim MC, Lee MH, Han SK, et al. Effects of Strengthening and Stretching Exercise for Individuals with Intrinsic Patellofemoral Pain Syndrome. J Korean Soc Phys Med. 2011;6(2):165-75.

Koh TJ. Do adaptations in serial sarcomere number occur with strength training? Hum Mov Sci. 1995;14(1): 61-77.

Konrad PA. Practical Introduction to Kinesiological Electromyography, Noraxon INC. USA. 2005.

Lacross ZT. Treatment Outcomes of Myofascial Decompression on Hamstring Pathology. 2014.

Lauche R, Cramer H, Choi KE, et al. The influence of a series of five dry cupping treatments on pain and mechanical thresholds in patients with chronic non-specific neck pain-a randomised controlled pilot study. BMC Complement Altern Med. 2011;11(1):1.

Law RY, Harvey LA, Nicholas MK, et al. Stretch exercises increase tolerance to stretch in patients with chronic musculoskeletal pain: a randomized controlled trial. Phys Ther. 2009;89(10):1016-26.

Malliaropoulos N, Papalexandris S, Papalada A, et al. The role of stretching in rehabilitation of hamstring injuries: 80 athletes follow-up. Med Sci Sports Exerc. 2004;36(5):756-9.

Marek SM, Cramer JT, Fincher AL, et al. Acute effects of static and proprioceptive neuromuscular facilitation stretching on muscle strength and power output. J Athl Train. 2005;40(2):94.

Meroni R, Cerri CG, Lanzarini C, et al. Comparison of active stretching technique and static stretching technique on hamstring flexibility. Clin J Sport Med. 2010; 20(1):8-14.

Michalsen A, Bock S, Lüdtke R, et al. Effects of traditional cupping therapy in patients with carpal tunnel syndrome: a randomized controlled trial. J Pain. 2009;10(6):601-8.

Musial F, Spohn D, Rolke R. Naturopathic reflex therapies for the treatment of chronic back and neck pain-Part 1: neurobiological foundations. Forsch Komplementmed. 2013;20(3):219-24.

Musumeci G. Could Cupping Therapy Be Used to Improve Sports Performance? J. Funct. Morphol. Kinesiol. 2016.

Muyor J, Alacid F, López-Miñarro P. Influence of hamstring muscles extensibility on spinal curvatures and pelvic tilt in highly trained cyclists. J Hum Kinet. 2011; 29:15-23.

Ries L. Cupping Therapy. Nurse Pract. 2016.

Rogan S, Wüst D, Schwitter T, et al. Static Stretching of the Hamstrings Muscle for Injury Prevention in Football Codes: a Systematic Review. Asian J Sports 
Med. 2013;4(1):1.

Schaible HG, Ebersberger A, Banchet GS. Mechanisms of pain in arthritis. Ann N Y Acad Sci. 2002;966(1): 343-54.

Schulte E. Acupuncture: Where East meets West. RN. 1996; 59(10):55-8.

Shenoy S, Mishra P, Sandhu JS. Comparison of the IEMG activity elicited during an isometric contraction using manual resistance and mechanical resistance. Ibnosina J Med BS. 2010;3(1):9-14.

Tham L, Lee H, Lu C. Cupping: from a biomechanical perspective. J Biomech. 2006;39(12):2183-93.

Witvrouw E, Danneels L, Asselman P, et al. Muscle flexibility as a risk factor for developing muscle injuries in male professional soccer players a prospective study. Am J Sports Med. 2003;31(1):41-6.

Ylinen JJ, Kautiainen HJ, Häkkinen AH. Comparison of active, manual, and instrumental straight leg raise in measuring hamstring extensibility. J Strength Cond Res. 2010;24(4):972-7.

Yoo SS, Tausk F. Cupping: east meets west. Int J Dermatol. 2004;43(9):664-5.

You YY, Lee BH. Effect of balance ability in the eldery women of motion-based game exercise program and stretching exercise program. J Korean Soc Phys Med. 2010; 5(4):667-74.

Zachazewski J. Improving flexibility. Physical Therapy. Philadelphia: JB Lippincott. 1989:698-9. 